\title{
ChemComm
}

\section{Enantioselective intramolecular propargylic amination using chiral copper-pybox complexes as catalysts $\dagger$}

\author{
Cite this: Chem. Commun., 2014, \\ 50, 7874 \\ Received 5th March 2014 \\ Accepted 22nd May 2014
}

DOI: $10.1039 / c 4 c c 01676 a$

www.rsc.org/chemcomm

\author{
Masashi Shibata, Kazunari Nakajima and Yoshiaki Nishibayashi*
}

\begin{abstract}
Intramolecular propargylic amination of propargylic acetates bearing an amino group at the suitable position in the presence of chiral copperpybox complexes proceeds enantioselectively to give optically active 1-ethynyl-isoindolines (up to $98 \%$ ee). The method described in this communication provides a useful synthetic approach to the enantioselective preparation of nitrogen containing heterocyclic compounds with an ethynyl group at the $\alpha$-position.
\end{abstract}

Heterocycles containing a nitrogen atom, such as pyrrolidines, tetrahydroquinolines and isoindolines, and their derivatives are widely found in many natural products and biologically active compounds. ${ }^{1}$ In addition to classical synthetic approaches to obtain these heterocycles, a variety of preparative methods catalyzed by transition metal complexes have been reported including their asymmetric version for the optically active heterocycles. ${ }^{1,2}$

In continuation of our study on the development of transition metal-catalyzed propargylic substitution reactions of propargylic alcohol derivatives with various nucleophiles including their enantioselective versions, ${ }^{3,4}$ we have recently disclosed the copper-catalyzed propargylic amination of propargylic esters with amines via copperallenylidene complexes as key reactive intermediates. ${ }^{5-7}$ In our reaction system, $(R)$-Cl-MeO-biphep was found to work as an effective ligand toward the propargylic amination with secondary amines such as $N$-methylaniline (Scheme $1(\mathrm{a})$ ), ${ }^{5}$ in contrast to van Maarseveen's reaction system, where the propargylic amination with primary amines was achieved by using diph-pybox as a chiral ligand (Scheme 1(b)). ${ }^{6}$ Based on these research backgrounds, we envisaged the application of this reaction system to the preparation of heterocycles containing a nitrogen atom via an intramolecular cyclization of propargylic esters bearing an amine moiety at a suitable position. In fact, we have succeeded in obtaining chiral 1-ethynyl-isoindolines in

Institute of Engineering Innovation, School of Engineering, The University of Tokyo, Yayoi, Bunkyo-ku, Tokyo, 113-8656, Japan. E-mail: ynishiba@sogo.t.u-tokyo.ac.jp; Fax: +813 5841-1175

$\dagger$ Electronic supplementary information (ESI) available. CCDC 989441. For ESI and crystallographic data in CIF or other electronic format see DOI: 10.1039/ c4cc01676a

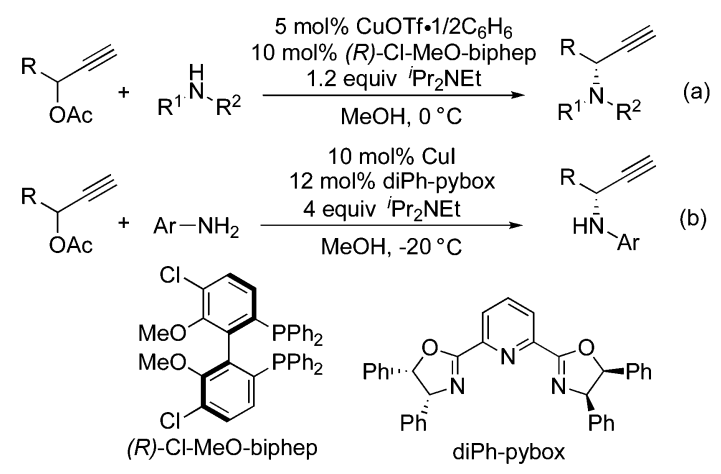

Scheme 1

good to high yields with up to $98 \%$ ee. Preliminary results are described here.

We have designed 1-phenylpropargylic acetates bearing an aminomethyl group at the ortho-position of the benzene ring $\mathbf{1}$, which were prepared via four steps from 2-bromobenzaldehyde, as shown in Scheme 2. After the protection of the original formyl group in 2-bromobenzaldehyde, the introduction of another formyl group and sequential ethynylation of the formyl group gave 1-(2-formylphenyl)prop-2-yn-1-yl acetate in a good yield. Then, reductive amination with various aniline derivatives led to the formation of $\mathbf{1}$ in high yields.

Treatment of 1-(2-((phenylamino)methyl)phenyl)prop-2-yn1 -yl acetate (1a) in methanol at room temperature for $14 \mathrm{~h}$ in

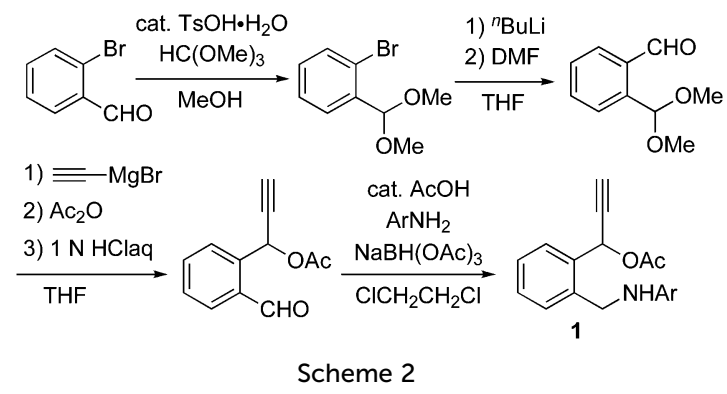

Scheme 2 
Table 1 Intramolecular propargylic amination of $1 \mathbf{a}$ in the presence of chiral copper complexes ${ }^{a}$

\begin{tabular}{|c|c|c|c|c|}
\hline \multirow[b]{2}{*}{ Entry } & 1a & \multicolumn{2}{|c|}{$\begin{array}{c}5 \text { mol\% CuOTf• } 1 / 2 \mathrm{C}_{6} \mathrm{H}_{6} \\
10 \text { mol\% Ligand } \\
1.2 \text { equiv }{ }^{i} \mathrm{Pr}_{2} \mathrm{NEt} \\
\underset{\mathrm{MeOH}, \mathrm{rt}, \text { Time }}{\longrightarrow}\end{array}$} & \multirow[b]{2}{*}{$\mathrm{ee}^{c}(\%)$} \\
\hline & Ligand & Time (h) & Yield of $\mathbf{2} \mathbf{a}^{b}(\%)$ & \\
\hline 1 & L1 & 14 & 17 & $57^{d}$ \\
\hline 2 & L2 & 4 & 19 & $55^{d}$ \\
\hline 3 & L3 & 20 & 2 & $17^{d}$ \\
\hline 4 & L4 & 4 & 80 & 89 \\
\hline 5 & L5 & 4 & 83 & 85 \\
\hline 6 & L6 & 4 & 81 & 82 \\
\hline 7 & L7 & 8 & 87 & 80 \\
\hline 8 & L8 & 20 & 25 & 56 \\
\hline 9 & L9 & 4 & 49 & 50 \\
\hline 10 & L10 & 4 & 82 & 23 \\
\hline 11 & L11 & 4 & 34 & $20^{d}$ \\
\hline $12^{e}$ & $\mathbf{L 4}$ & 8 & 87 & 93 \\
\hline $13^{f}$ & L4 & 20 & 87 & 93 \\
\hline $14^{e}$ & L5 & 8 & 91 & 90 \\
\hline
\end{tabular}

${ }^{a}$ Reactions of $1 \mathrm{a}(0.2 \mathrm{mmol})$ in the presence of CuOTf $1 / 2\left(\mathrm{C}_{6} \mathrm{H}_{6}\right)$ $(0.01 \mathrm{mmol})$, ligand $(0.02 \mathrm{mmol})$, and ${ }^{\mathrm{i}} \mathrm{Pr}_{2} \mathrm{NEt}(0.24 \mathrm{mmol})$ were carried out in $\mathrm{MeOH}$ at room temperature. ${ }^{b}$ Isolated yield. ${ }^{c}$ Determination by HPLC. ${ }^{d}$ The opposite absolute configuration $(1 S)$ was found. ${ }^{e}$ At $0{ }^{\circ} \mathrm{C} .{ }^{f} \mathrm{At}-10^{\circ} \mathrm{C}$.

the presence of $5 \mathrm{~mol} \%$ of CuOTf $\cdot 1 / 2\left(\mathrm{C}_{6} \mathrm{H}_{6}\right)$ and $10 \mathrm{~mol} \%$ of (R)-Cl-MeO-biphep ${ }^{8}$ (L1) gave 1-ethynyl-2-phenylisoindoline (2a) in $17 \%$ yield with $57 \%$ ee (Table 1 , entry 1 ). Typical results are shown in Table 1. The use of related diphosphines such as $(R)$-binap ${ }^{9}(\mathbf{L} 2)$ and $(R)$-segphos ${ }^{10}(\mathbf{L} 3)$ as chiral ligands afforded only low yields of 2a (Table 1, entries 2 and 3). When pyboxs were used as chiral ligands under the same reaction conditions, the intramolecular amination proceeded smoothly to give $\mathbf{2 a}$ in good to high yields with a high enantioselectivity. The use of a larger amount ( 2 equiv. to $\mathrm{Cu}$ atom) of pyboxs slightly increased the enantioselectivity in all cases. $(S)$-Me-pybox ${ }^{11}(\mathbf{L} 4)$ was found to work as an effective chiral ligand to achieve the highest enantioselectivity, i.e. $89 \%$ ee (Table 1, entry 4) although the use of related pyboxs such as Ph-pybox $^{11}$ (L5), ${ }^{\text {Pr-pybox }}{ }^{11}$ (L6), and Bn-pybox ${ }^{11}$ (L7) gave high enantioselectivities (85\% ee, $82 \%$ ee, and $80 \%$ ee, respectively) (Table 1, entries 5-7). Other pyboxs such as $t$ Bu-pybox $^{11}$ (L8), indan-pybox $^{11}$ (L9), and diPh-pybox ${ }^{6}$ (L10) did not work as effective ligands, with only low to moderate enantioselectivities (56\% ee, 50\% ee, and $23 \%$ ee, respectively) (Table 1 , entries 8-10). When a bis(oxazoline) ligand ${ }^{12}$ (L11) was used as a chiral ligand, the amination did not occur smoothly, affording 2 a with only a low enantioselectivity (Table 1, entry 11). A higher enantioselectivity was observed

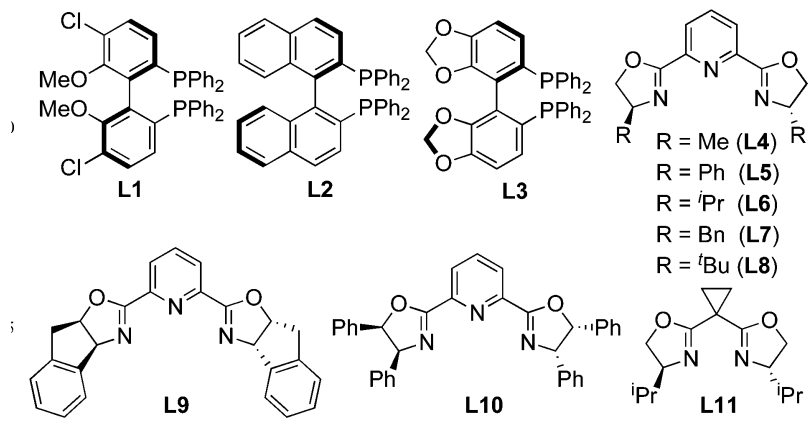

when the cyclic amination was carried out at a lower reaction temperature by using $\mathbf{L} \mathbf{4}$ and $\mathbf{L 5}$ as chiral ligands. The highest enantioselectivity was achieved at $0{ }^{\circ} \mathrm{C}$ and $-10{ }^{\circ} \mathrm{C}$ by using $\mathrm{LA}$ (Table 1, entries 12 and 13). A slightly lower enantioselectivity was observed in the reaction at $0{ }^{\circ} \mathrm{C}$ by using $\mathbf{L 5}$ as a chiral ligand (Table 1, entry 14).

Intramolecular cyclic amination of various propargylic acetates bearing an aminomethyl group was investigated by using $\mathbf{L}$ and $\mathbf{L 5}$ as chiral ligands. Typical results are shown in Table 2. The presence of a substituent such as a methyl, fluoro, or bromo group at the paraposition of the benzene ring in the amino group decreased the reactivity, a longer reaction time (20-30 h) being necessary to obtain the corresponding 1-ethynyl-isoindolines in high yields with a high enantioselectivity (Table 2, entries 1-6). The highest enantioselectivity was achieved in the reaction of $\mathbf{1 d}$ as a substrate by using $\mathbf{L 5}$ (Table 2, entry 8). After one recrystallization of crude cyclic product, the enantiomerically pure $\mathbf{2 d}$ was isolated and its absolute configuration $(1 R)$ was determined by X-ray analysis (Fig. 1$){ }^{13}$

Next, we investigated the nature of substituents on the aromatic scaffold linking the propargylic acetate. Typical results are shown in scheme 3. The introduction of a fluoro group at the 5-position and two methoxy groups at the 4- and 5 -positions substantially increased the enantioselectivity under the same reaction conditions.

As described in our previous work, the intermolecular propargylic amination proceeded via copper-allenylidene complex (I) ${ }^{5,6,14}$ which was generated from the copper-pybox complex with the propargylic acetate. At present, we consider

Table 2 Intramolecular propargylic amination of $\mathbf{1}$ in the presence of chiral copper complexes ${ }^{a}$

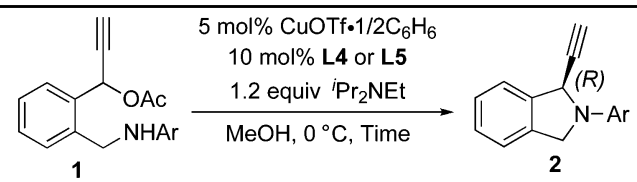

\begin{tabular}{|c|c|c|c|c|c|}
\hline Entry & 1, Ar & Ligand & Time (h) & Yield of $2^{b}(\%)$ & $\mathrm{ee}^{c}(\%)$ \\
\hline 1 & $1 a, \mathrm{C}_{6} \mathrm{H}_{5}$ & L4 & 8 & 87 & 93 \\
\hline 2 & $1 \mathrm{a}, \mathrm{C}_{6} \mathrm{H}_{5}$ & L5 & 8 & 91 & 90 \\
\hline 3 & $\mathbf{1 b}, 4-\mathrm{MeC}_{6} \mathrm{H}_{4}$ & L4 & 20 & 79 & 92 \\
\hline 4 & 1b, $4-\mathrm{MeC}_{6} \mathrm{H}_{4}$ & L5 & 20 & 70 & 92 \\
\hline 5 & 1c, $4-\mathrm{FC}_{6} \mathrm{H}_{4}$ & L4 & 30 & 79 & 95 \\
\hline 6 & 1c, $4-\mathrm{FC}_{6} \mathrm{H}_{4}$ & L5 & 30 & 77 & 88 \\
\hline 7 & 1d, $4-\mathrm{BrC}_{6} \mathrm{H}_{4}$ & L4 & 30 & 89 & 93 \\
\hline 8 & 1d, $4-\mathrm{BrC}_{6} \mathrm{H}_{4}$ & L5 & 30 & 89 & 96 \\
\hline
\end{tabular}

${ }^{a}$ Reactions of $1(0.2 \mathrm{mmol})$ in the presence of CuOTf $\cdot 1 / 2\left(\mathrm{C}_{6} \mathrm{H}_{6}\right)$ $(0.01 \mathrm{mmol}), \mathbf{L} 4$ or $\mathbf{L 5}(0.02 \mathrm{mmol})$, and ${ }^{\mathrm{i}} \mathrm{Pr}_{2} \mathrm{NEt}(0.24 \mathrm{mmol})$ were carried out in $\mathrm{MeOH}$ at $0{ }^{\circ} \mathrm{C} .{ }^{b}$ Isolated yield. ${ }^{c}$ Determination by HPLC.

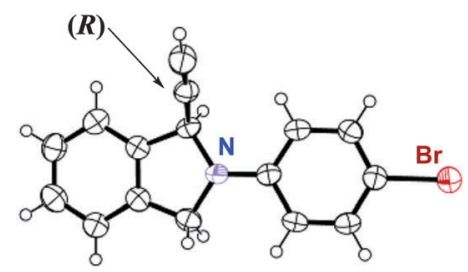

Fig. 1 Ortep drawing of optically active $\mathbf{2 d}$. 


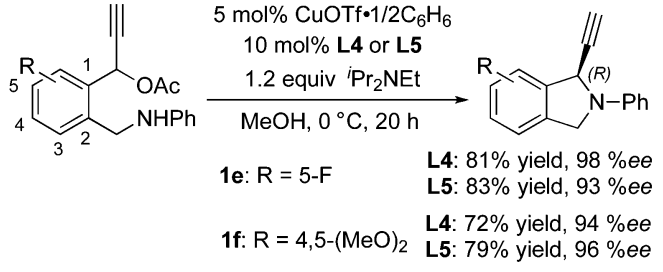

Scheme 3

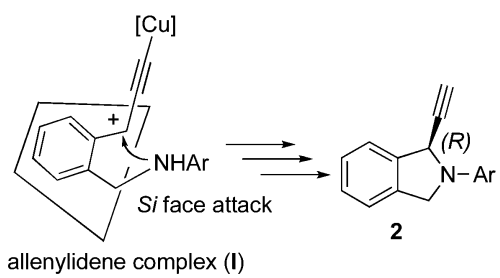

Fig. 2 Copper-allenylidene complex as a key reactive intermediate.

that the intramolecular amination also proceeds via a similar reaction pathway. The absolute configuration at the propargylic position in 2 indicates that the intramolecular attack of an amino group on the cationic $\gamma$-carbon in $\mathbf{I}$ occurs from the $S i$ face (Fig. 2).

The successful results of the intramolecular cyclic amination prompted us to investigate double propargylic amination including sequential inter- and intra-molecular amination (Scheme 4). The reaction of 1,1'-(1,2-phenylene)-bis(prop-2yne-1,1-diyl) diacetate (3) with aniline in methanol at room temperature in the presence of $5 \mathrm{~mol} \%$ of CuOTf $\cdot 1 / 2\left(\mathrm{C}_{6} \mathrm{H}_{6}\right)$ and $10 \mathrm{~mol} \%$ of $\mathbf{L 5}$ proceeded smoothly to give 1,3-di(ethynyl)-2phenylisoindoline (4a) in $70 \%$ yield as a mixture of two diastereoisomers (meso-isomer/DL-isomer $=5 / 1$ ) (Scheme 4(a)). The minor DL-isomer was obtained with $75 \%$ ee. On the other hand, the reaction of 3 with $N, N^{\prime}$-diphenylethane-1,2-diamine under the same reaction conditions afforded 1,6-diethynyl-2,5-diphenyl$1,2,3,4,5,6$-hexahydrobenzo[ $f][1,4]$ diazocine (4b) in $68 \%$ yield as a mixture of two diastereoisomers (meso-isomer/DL-isomer $=8 / 1$ ) (Scheme 4(b)). The minor DL-isomer was obtained with $66 \%$ ee. The low selective formation of DL-isomers in the both reaction systems indicates that the first intermolecular amination of 3 took
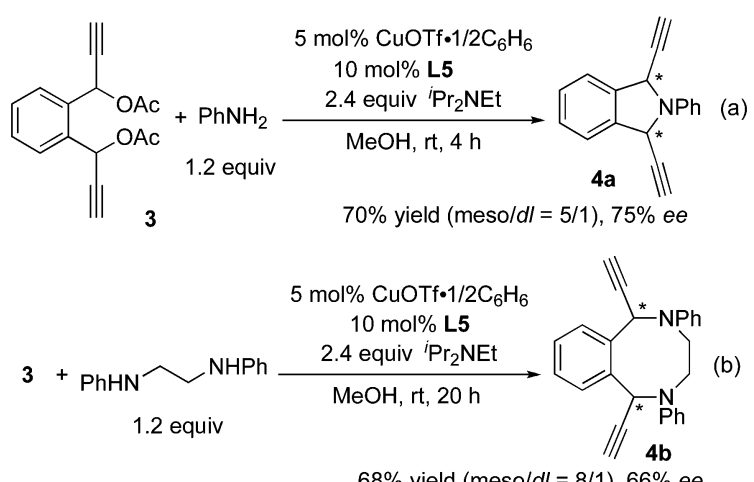

$68 \%$ yield $($ meso/dl $=8 / 1), 66 \%$ ee

Scheme 4 place with only a low enantioselectivity. This low selectivity was not surprising based on the results found by van Maarseveen and co-workers for the intermolecular amination with primary aniline by using Ph-pybox. ${ }^{6}$

In summary, we have disclosed the copper-catalyzed intramolecular propargylic amination of propargylic acetates bearing an amine moiety at a suitable position to give optically active 1-ethynyl-isoindolines. In the present reaction system, copper-pybox complexes have been found to work as effective catalysts toward the propargylic amination (up to $98 \%$ ee). We believe that the present method provides a useful synthetic approach to the enantioselective preparation of optically active nitrogen containing heterocyclic compounds with an ethynyl group at the $\alpha$-position with a high enantioselectivity as an application of the copper-catalyzed propargylic amination. Further studies on the transition metal-catalyzed propargylic substitution reactions are currently in progress.

\section{Notes and references}

1 For reviews, see: (a) M. Chrzanowska and M. D. Rozwadowska, Chem. Rev., 2004, 104, 3341; (b) Y.-G. Zhou, Acc. Chem. Res., 2007, 40, 1357; (c) S. Anas and H. B. Kagan, Tetrahedron: Asymmetry, 2009, 20, 2193; (d) M. Ahamed and M. H. Todd, Eur. J. Org. Chem., 2010, 5935; (e) V. Sridharan, P. A. Suryavanshi and J. C. Menéndez, Chem. Rev., 2011, 111, 7157.

2 For enantioselective synthesis of isoindolines, see: (a) Y. Sato, T. Nishimata and M. Mori, J. Org. Chem., 1994, 59, 6133; (b) Y. Sato, T. Nishimata and M. Mori, Heterocycles, 1997, 44, 443; (c) D. Enders, A. A. Narine, F. Toulgoat and T. Bisschops, Angew. Chem., Int. Ed., 2008, 47, 5661; (d) C. Wang, X.-H. Chen, S.-M. Zhou and L.-Z. Gong, Chem. Commun., 2010, 46, 1275; (e) S. Takizawa, N. Inoue, S. Hirata and H. Sasai, Angew. Chem., Int. Ed., 2010, 49, 9725; $(f)$ R. Morán-Ramallal, V. Gotor-Fernández, P. Laborda, F. J. Sayago, C. Cativiela and V. Gotor, Org. Lett., 2012, 14, 1696.

3 For our recent reviews, see: $(a)$ Y. Miyake, S. Uemura and Y. Nishibayashi, ChemCatChem, 2009, 1, 342; (b) Y. Nishibayashi, Synthesis, 2012, 489.

4 For recent reviews by other research groups, see: (a) R. J. Detz, H. Hiemstra and J. H. van Maarseveen, Eur. J. Org. Chem., 2009, 6263; (b) C.-H. Ding and X.-L. Hou, Chem. Rev., 2011, 111, 1914; (c) O. Debleds, E. Gayon, E. Vrancken and J.-M. Campagne, Beilstein J. Org. Chem., 2011, 7, 866; (d) E. B. Bauer, Synthesis, 2012, 1131.

5 For our recent papers of enantioselective propargylic amination, see: (a) G. Hattori, H. Matsuzawa, Y. Miyake and Y. Nishibayashi, Angew. Chem., Int. Ed., 2008, 47, 3781; (b) G. Hattori, A. Yoshida, Y. Miyake and Y. Nishibayashi, J. Org. Chem., 2009, 74, 7603; (c) G. Hattori, Y. Miyake and Y. Nishibayashi, ChemCatChem, 2010, 2, 155; (d) G. Hattori, K. Sakata, H. Matsuzawa, Y. Tanabe, Y. Miyake and Y. Nishibayashi, J. Am. Chem. Soc., 2010, 132, 10592; (e) A. Yoshida, M. Ikeda, G. Hattori, Y. Miyake and Y. Nishibayashi, Org. Lett., 2011, 13, 592; $(f)$ A. Yoshida, G. Hattori, Y. Miyake and Y. Nishibayashi, Org. Lett., 2011, 13, 2460.

6 For recent papers of enantioselective propargylic amination reported by van Maarseveen and co-workers, see: (a) R. J. Detz, M. M. E. Delville, H. Hiemstra and J. H. van Maarseveen, Angew. Chem., Int. Ed., 2008, 47, 3777; (b) R. J. Detz, Z. Abiri, R. le Griel, H. Hiemstra and J. H. van Maarseveen, Chem. - Eur. J., 2011, 17, 5921.

7 For recent papers of enantioselective propargylic amination reported by other research groups, see: (a) C. Zhang, Y.-H. Wang, X.-H. Hu, Z. Zheng, J. Xu and X.-P. Hu, Adv. Synth. Catal., 2012, 354, 2854; (b) T. Mino, H. Taguchi, M. Hashimoto and M. Sakamoto, Tetrahedron: Asymmetry, 2013, 24, 1520.

8 (R)-Cl-MeO-biphep = $(R)-5,5^{\prime}$-dichloro-6, $6^{\prime}$-dimethoxy-2,2' ${ }^{\prime}$-bis $($ diphenylphosphino)-1,1'-biphenyl: (a) R. R. Huddleston, H.-Y. Jang and M. J. Krische, J. Am. Chem. Soc., 2003, 125, 11488; (b) H.-Y. Jang, F. W. Hughes, H. Gong, J. Zhang, J. S. Brodbelt and M. J. Krische, J. Am. Chem. Soc., 2005, 127, 6174; (c) J. U. Rhee and M. J. Krische, J. Am. 
Chem. Soc., 2006, 128, 10674; (d) E. Skucas, J. R. Kong and M. J. Krische, J. Am. Chem. Soc., 2007, 129, 7242.

9 (R)-binap $=(R)-2,2^{\prime}$-bis(diphenylphosphino)-1,1'-binaphthyl: R. Noyori and H. Takaya, Acc. Chem. Res., 1990, 23, 345 and references therein.

$10(R)$-segphos = $(R)-5,5^{\prime}$-bis(diphenylphosphino)-4,4'-bi-1,3-benzodioxole: H. Shimizu, I. Nagasaki, K. Matsumura, N. Sayo and T. Saito, Acc. Chem. Res., 2007, 40, 1385 and references therein.

11 pybox = Pyridine-2,6-bis(oxazolines): G. Desimoni, G. Faita and P. Quadrelli, Chem. Rev., 2003, 103, 3119.
12 For a recent review on bis(oxazoline) ligands, see: G. Desimoni, G. Faita and K. A. Jørgensen, Chem. Rev., 2006, 106, 3561.

13 See ESI $\dagger$ for Experimental details.

14 (a) The copper-allenylidene complexes have not yet been isolated and characterized until now although silver- and gold-allenylidene complexes have already been reported by Bertrand and Hashmi, respectively; (b) M. Asay, B. Donnadieu, W. W. Schoeller and G. Bertrand, Angew. Chem., Int. Ed., 2009, 48, 4796; (c) M. M. Hansmann, F. Rominger and A. S. K. Hashmi, Chem. Sci., 2013, 4, 1552. 